\title{
The Place of Context: A Theory and Strategy for Criminology's Hard Problems
}

\section{Citation}

Sampson, Robert J. 2013. “The Place of Context: A Theory and Strategy for Criminology's Hard Problems." Criminology 51 (1) (February 24): 1-31. doi:10.1111/1745-9125.12002. http:// dx.doi.org/10.1111/1745-9125.12002.

\section{Published Version}

doi:10.1111/1745-9125.12002

\section{Permanent link}

http://nrs.harvard.edu/urn-3:HUL.InstRepos:11324028

\section{Terms of Use}

This article was downloaded from Harvard University's DASH repository, and is made available under the terms and conditions applicable to Open Access Policy Articles, as set forth at http:// nrs.harvard.edu/urn-3:HUL.InstRepos:dash.current.terms-of-use\#OAP

\section{Share Your Story}

The Harvard community has made this article openly available.

Please share how this access benefits you. Submit a story.

Accessibility 


\section{CRIMINOLOGY 51:1-31 (February, 2013)}

Final published version: http://onlinelibrary.wiley.com/doi/10.1111/1745-9125.12002/abstract

Copyright $(\mathcal{C} 2013$ by the American Society of Criminology

2012 Presidential Address to the American Society of Criminology

THE PLACE OF CONTEXT:

A THEORY AND STRATEGY FOR CRIMINOLOGY'S HARD PROBLEMS*

Keywords: context, place, neighborhood effects, inequality

\section{ROBERT J. SAMPSON}

Department of Sociology and the Radcliffe Institute for Advanced Study, Harvard University

*Direct correspondence to Robert J. Sampson, Department of Sociology, William James Hall, Harvard University, 33 Kirkland Street, Cambridge, MA 02138 (rsampson@,wjh.harvard.edu) 


\begin{abstract}
I present a theoretical framework and analytic strategy for the study of place as a fundamental context in criminology, with a focus on neighborhood effects. My approach builds on research over the past 15 years from the Project on Human Development in Chicago Neighborhoods and a recent book unifying the results. I argue that "ecometrics" can be applied at multiple scales and I elaborate core principles and guiding hypotheses for five problems: (1) legacies of inequality and developmental neighborhood effects; (2) race, crime, and the new diversity; (3) cognition and context, above all the social meaning of disorder; (4) the measurement and sources of collective efficacy in a cosmopolitan world; and (5) higher-order structures beyond the neighborhood that arise in complex urban systems. Although conceptually distinct, these hard problems are interdependent and ultimately linked to a frontier in criminology: contextual causality.
\end{abstract}


The thesis I advance in this address is that place - especially as manifested in neighborhoods - is a fundamental context that has widespread effects on crime, perceptions of order and disorder, well-being, and much more, including the social organization of the contemporary metropolis. In a recently published book, Great American City: Chicago and the Enduring Neighborhood Effect (Sampson 2012), I introduced this thesis by asking the reader to imagine the very opposite- "placelessness" and the alleged "death of distance" in an increasingly flat world.

On a first try such a world is easy to picture because it confronts us every day. Technology seduces us to transcend place and indeed the streets are filled with people plugged in to anywhere but where they are. If our devices allow us to be elsewhere, aren't the particularities of our somewhere irrelevant? The globalization of culture and travel are pervasive, further eroding local boundaries. We have also been told, for some time now, that traditional forms of community have withered away under the assault of globalization, technological change, and urbanization. By these accounts, the local, place, neighborhood—-they do sound a bit quaint. But something is amiss in this picture. While globalization and technological advances are real, the world is profoundly uneven and inequality by place is itself ubiquitous. In a seeming paradox, for example, the data reveal that neighborhood segregation by income has increased, not decreased, along with globalization (Fry and Taylor 2012; Reardon and Bischoff 2011). Commitment to community is also found and argued about in cities everywhere. Whether by race, sexual orientation, or social status, identities of place motivate action across the political spectrum, even in our most global of cities. As the urban theorist Manual Castells (2000: 697) puts it, "most of New York, in fact most of Manhattan, is very local, not global."

To experience the diversity and distinctiveness of contemporary neighborhoods up close, in the first chapter of the book I take the reader on a walk down the streets of Chicago and 
describe the varied scenes. I begin in the sparkling "Magnificent Mile" just off the Gold Coast and then walk south through the high-rise Loop, the gentrifying Near South Side, an empty field formerly the ill-famed Robert Taylor Homes, racially integrated Hyde Park, a Woodlawn slum cheek by jowl with middle class renewal, and stable working-class neighborhoods. I then zoom out to a city-wide view of Chicago over multiple decades. I show that clustering by neighborhood and community takes in a broad sweep of sometimes disparate social phenomena. Whether crime, poverty, infant health, protest, civic engagement, leadership networks, or collective efficacy, the city is ordered by a spatial logic ("placed") and yields differences as much today as a century ago. Neighborhoods are always changing, but their relative position or place in the status hierarchy of the city is remarkably persistent over time.

My street-level observations combined with a temporal view of Chicago from above highlight three interrelated facts: The first is neighborhood concentration and hence the spatial inequality of everyday life. The second is the tendency of diverse social phenomena to cluster together in space- "things go together." The third is persistence despite change, or more generally the neighborhood-level social structure of the city. I go on to articulate an overarching theory of context and neighborhood effects, backed by empirical results from 15 years of research in Chicago.

I seek here to build on this framework. I begin by briefly and selectively reviewing the theoretical principles, methodological strategy, and findings in Great American City (Sampson, 2012). I paint the big picture in broad strokes, consistent with the nature of a Presidential Address. ${ }^{1}$ My main objective, however, is to look forward. Framed by the book's theory and findings but pushing ahead, I pose areas of research and unresolved questions that constitute

1. For purposes of overview and synthesis, I draw mainly from chapters 3 and 15 in Sampson (2012). 
frontiers in our field — what we might think of as criminology's "hard problems."2 Let me be clear: Mine is not another claim of the "crisis of criminology." Although hard, the problems and puzzles I define are potentially solvable and that is what makes them, and the field, exciting. I thus offer this address not as a critique of past research, but in a generative spirit, one that reaches for new ideas, guiding hypotheses, and an agenda for moving criminology forward. ${ }^{4}$

\section{PRINCIPLES OF INQUIRY AND CORE CONCEPTS}

The great student of the city Lewis Mumford once said, "Neighborhoods, in some primitive, inchoate fashion exist wherever human beings congregate" (1954: 258). Half a century later the archaeologist Michael Smith agrees. Based on research around the world, Smith (2010: 137) argues that the "spatial division of cities into districts or neighborhoods is one of the few universals of urban life from the earliest cities to the present." The salience of neighborhood difference has persisted across long time scales and historical eras despite the transformation of specific boundaries, political regimes, and the layout of cities. The consistency of neighborhood differentiation from ancient cities to contemporary Chicago suggests that spatial inequality is an enduring mechanism that constitutes a fundamental organizing dimension of human behavior.

2. In the conclusion I return to the idea of "hard problems" and its ultimate charge as famously set out by the mathematician David Hilbert over a century ago. Unlike Hilbert, however, I do not seek to lay out all the problems of the discipline. My selections are framed in light of my overarching concern with context.

3. Each generation of criminologists seems to identify a different crisis, a common intellectual tradition across disciplines. Over forty years ago, for example, Gouldner (1970) warned of the "Coming Crisis in Western Sociology." Depending on the observer, sociology has been in crisis ever since or well before Gouldner's attack. The point is that crisis is not the same as deep intellectual challenges. Quite the opposite - an intellectual discipline without hard problems is complacent and boring.

4. For this reason, I dedicate my address to younger scholars, especially graduate students. More than most, you are the future and well poised to make the next set of breakthroughs. 
In Great American City (GAC) I therefore reject intellectual moves toward placelessness and revised traditional "bottom-up approaches" (it's all the individual) and "top-down" approaches (it's all structure) to argue that neighborhoods are not merely the settings in which individuals enact autonomous decisions or follow preset scripts, and that neighborhoods are not merely empty vessels determined by external or global forces. I argue instead that neighborhood contexts are important determinants of the quantity and quality of human behavior in their own right. I also argue that differentiation by neighborhood is not only everywhere to be seen, but that it is has durable properties with effects that span a wide variety of social phenomena. I thus expand the traditional focus of neighborhood effects on individuals to examine a family of neighborhood effects across multiple units of analysis, outcomes, and time scales. In making this intellectual move, the idea of neighborhood effects commands a broader scope, ranging from individual cognition and perceptions to the higher-order social structure of the city.

My argument is guided by ten overarching principles that motivated a series of specific hypotheses and empirical tests. I believe these general principles can motivate new criminological inquiry as well. The first principle is the most basic:

(1) Relentlessly focus on context, especially concentrated neighborhood inequality and social stratification by place.

(2) Study neighborhood-level variations in their own right and adopt a systematic method of data collection that relies on multiple methods with public standards of measurementmetrics for ecology or what Stephen Raudenbush and I called "ecometrics."

(3) Focus on social-interactional, social-psychological, organizational, and cultural mechanisms of city life rather than just individual attributes or traditional compositional features like racial makeup and class-in short, social mechanisms that link cause and effect. In the book 
I focus mainly on collective efficacy, perceptions of disorder, legal cynicism, social altruism and organizational capacity as key theoretical concepts that in different ways explain crime rates.

(4) Study dynamic processes of neighborhood structural change.

(5) Simultaneously assess mechanisms of social reproduction and cultural continuity.

(6) Embed in the study of neighborhood dynamics the role of individual selection, both its contextual sources and social consequences (or macro outcomes). I claim that what we typically think of as selection "bias" is misguided — selection is a neighborhood effect.

(7) At the same time, go beyond both the individual and the local to examine spatial mechanisms that cross neighborhood boundaries. Spatial disadvantage, not just internal neighborhood characteristics, is important for understanding a neighborhood's crime rate.

(8) Further yet, study the social and cultural organization of the metropolis as a whole, including higher-order structures that create cross-cutting links beyond spatially proximate neighborhoods.

(9) Never lose sight of human concerns with public affairs and the improvement of city life—develop implications for community-level interventions. I argue for place-based interventions as a principled alternative to people-based approaches to reducing crime.

(10) Last, but not least, emphasize theoretically motivated and interpretive empirical research while taking a pluralistic stance on the nature of evidence needed to assess social causation-what I eventually came to call "contextual causality."

\section{THE CHICAGO PROJECT}

Based on these principles of theory and method, I developed a number of more explicit hypotheses and strategies that were explored in what I called the Chicago Project. By the latter I mean a number of connected studies, all of which focus on Chicago circa the late 20th and early 
21 st centuries. The effort that unites them and the empirical base of the book is the "Project on Human Development in Chicago Neighborhoods" (PHDCN), an original longitudinal study of children, families, and neighborhoods in what is one of the most American cities and thus representative at heart—a microcosm for the study of urban contexts. ${ }^{5}$ But the PHDCN contains multiple components that in turn spawned cognate studies with independent intellectual standing and that I integrated and expanded; hence the name "Chicago Project." The project has the following key features, the first three of which represent the core activities of PHDCN:

- A longitudinal cohort study of approximately 6,200 children and families followed wherever they moved in the United States for up to seven years.

- A representative community survey of more than 8,000 Chicago residents in 1995 and another survey in 2002 of over 3,000 residents.

- A systematic social observational study (through videotaping) of more than 20,000 street segments in a sample of neighborhoods purposely chosen to vary by race/ethnicity and SES, along with a follow-up observational study by raters seven years later across the entire city.

- A Network Panel Study of more than 2,800 key leaders in forty-seven communities, interviewed in 1995 and again in a 2002 follow-up of over 1,000 leaders.

- A study of more than 4,000 collective action events in the Chicago metropolitan area from 1970 to 2000.

- A "field experiment" in 2002 and 2010 designed to measure community-level differences in the propensity of people in public settings to mail back "lost letters."

These data sources were combined with archival records on crime, violence, health (e.g., mortality, birth weight, and teenage pregnancy), housing, community organizations, and a wealth

5. Chapter 4 in the book describes in detail the history of PHDCN, its design and data collection, and the many unselfish individuals whose long-term commitment of labor made the project succeed. 
of population characteristics from the U.S. Census across several decades. I also spent many years observing and thinking about Chicago during my daily rounds, and I conducted interviews with community leaders up to 2008 .

In short, Great American City integrates the study of neighborhood structural inequality, social and cultural mechanisms, spatial dynamics, and the higher-order structures of the city. Hence a disclaimer: Mine is not a theory of crime per se. But this may be an advantage given the surfeit of crime causation theories in criminology. I offer instead a theory of context that is

broadly applicable to multiple social outcomes, with a crime a leading test case (Sampson, 2012: 355). Having outlined the project's contours, I turn now to a discussion of how the book's concepts and strategies can address some of criminology's hard problems and formulate new questions. But first it is necessary to address my conception of place and definition of neighborhood. The latter is often said to be the oldest problem in neighborhood research.

\section{THE IDEA OF NEIGHBORHOOD}

Almost a century ago, the sociologist Roderick McKenzie stated: "Probably no other term is used so loosely or with such changing content as the term neighborhood, and very few concepts are more difficult to define" (McKenzie 1921: 344-345). Since then hundreds of operational definitions have been proposed but the perceived problem continues. Indeed, it is not uncommon to find hand-wringing over the "right" operational definition of neighborhood and skirmishes among devotees of competing units of analysis. Some go for big units (e.g., community areas, health districts, cities even) while others want them small, like block groups or census blocks. A recent move argues for even smaller or "micro places," as small as a street corner or a house (Weisburd et al. 2012). Most researchers are pragmatic and go for census tracts, a workhorse of 
neighborhood effects research for generations and for good reason — the availability of decades of detailed census data at the tract level yields an enormous treasure trove.

I argue, however, that the empirical search for the correct operational definition of neighborhood or place is misplaced. For one thing, the concept of place ranges over units big and small. Merriam-Webster's dictionary, for example, defines place to include areas as small as a building or as large as "a particular region" or "center of population." Thus Chicago is a place, but so is the Hyde Park community surrounding the University of Chicago, and within that "Jimmy's," a wonderful watering hole at East $55^{\text {th }}$ and S. Woodlawn.

The phenomenon of crime does not privilege any one type of place or ecological unit either. Crime varies within societies, states, counties, cities and certainly within neighborhoods, whether measured at the level of census tracts or even block groups. But crime varies within smaller places too — most apartments on a high burglary street are not burglarized, for example. Within an apartment complex, crime risk varies by apartment, and so on almost like an infinite regress problem. Internal variance thus does not logically imply that a lower (micro) level is inherently better than a higher (macro) level. Why Chicago is more violent than say, Stockholm Sweden is just as important a question as why violence differs by places within a neighborhood.

I also argue that how micro places are perceived or reacted to by residents and authorities alike is conditioned by the larger context. A vacant house in one neighborhood can evoke reactions very different than in another neighborhood—as I will turn to later, the meaning of disorder is shaped by its surrounding context. In particular, micro places and even conventional neighborhoods are nested within larger communities that are recognized or named by residents, external housing buyers, and institutional actors such as real estate agents and administrative

6. http://www.merriam-webster.com/dictionary/place. 
agencies such as the police. These larger-scale perceptual, organizational, and political factors govern how reactions at the more micro level unfold. Razing a drug house or closing a rowdy bar is a complex act, for example, that is about much more than the place itself. It matters what neighborhood the house or bar is in —what "kinds of people" reside there, what the zoning laws are, how vocal the residents are, and how decision-makers view the area.

Equally important and related is the symbolic power or idea of neighborhood. While social scientists quibble over empirical definitions and clear boundaries, citizens make decisions and render opinions every day based on broad perceptions and imagined neighborhoods, which in turn have real consequences. Novelists, artists, news columnists, and outside observers of all political stripes also use the term "neighborhood" not to signify neat quantified definitions so much as to reflect symbolic differences inscribed in space (Gieryn 2000). ${ }^{7}$

Place is thus a fluid rather than fixed concept, but research has to start somewhere. In my own criminological research I have examined primarily cities, communities, and neighborhoods, with the latter taking up my current focus. In that work I conceptualize neighborhood in theoretical terms as a geographic and hence ecological section of a larger community or region that usually contains residents or institutions and that has socially distinctive characteristics. This definition highlights the general characteristic of neighborhoods from ancient cities to the present—-they are embedded analytic units with simultaneous social and spatial significance. An empirical implication follows - if there is no differentiation (or clustering) by social characteristics based on the proposed geography, there is no neighborhood in the socially

7. Appropriation of the idea of neighborhood does not favor any ideological side. As a historian of the city has argued, the "language of neighborhood communalism is a place where traditional distinctions among left, liberal, and right often blur or even crumble" (Looker 2012: 577). Thus segregationists defend "pure" neighborhoods while anarchists or radicals claim utopian ideals. Even Norman Mailer got in on the act, running for mayor of New York City under the campaign of "Neighborhood Power." The city and neighborhood are also surprisingly central to much of English literature (Jaye and Watts 1981). 
meaningful sense. The evidence is in: Research has consistently demonstrated considerable social inequality across multiple levels of neighborhood analysis (Sampson 2012: chapter 2, 5).

The apparent problem of defining neighborhood is thus amenable to solution: Ecometrics (principle 2) is applicable or scalable to multiple levels of place, negating the perceived need for a single definition. ${ }^{8}$ Moreover, I define social characteristics (e.g., local ties, perceptions) separately from the unit of analysis. Similar to Janowitz's (1967) concept of the community of limited liability, traditional "neighborhoodness" in the form of tight-knit ties among neighbors is not necessary to define a neighborhood (and in any case is rare). Note further that neighborhoods of residence are but one concern—neighborhoods of work and play are relevant too. This pragmatic conceptualization allows empirical research to proceed without tautology and it offers a menu of options for measuring theoretical constructs across place-based units of analysis. Depending on the question, large or small units may be relevant (Hipp 2007). ${ }^{9}$ And like assumptions in a theoretical model, definitions of neighborhood are almost always unrealistic or "wrong," but they are more or less useful in generating insights about the world and yielding testable empirical predictions.

\section{"BIG DATA” AND THE TECHNOLOGY CHALLENGE}

There is more good news. Advances in technology said to undermine community are instead providing us with increased geographical flexibility and power to measure social characteristics across multiple spatial scales. Mobile phone apps have created a flood of new geo-referenced data on everything from potholes to crime (Giles 2012), and the technology

8. Raudenbush and Sampson (1999) examine ecometric strategies and statistical properties more formally by various levels of ecological aggregation and measurement source.

9. In the PHDCN, I have relied primarily on census block groups, tracts, neighborhood clusters of census tracts that are socially and ecologically similar, and community areas, which in Chicago are socially and symbolically distinctive areas about 38,000 residents on average (Sampson, 2012: Chapter 3). 
giants Google and Apple are competing intensely over none other than maps. The "Boston Area Research Initiative" (BARI) is an example of a recent effort to capitalize on technological advances to spur original research on neighborhoods and increase collaborations between government agencies and academics. ${ }^{10}$ Combined with advances in GPS digital mapping from the communications revolution (e.g., tracing the physical movement of individuals through cellphone usage), spatial statistics and mapping tools, ${ }^{11}$ and new measures of routine activities in time and space such as time budgets (Wikström et al. 2012), the possibilities are extensive for creating rich databases of neighborhood and other place-based contexts.

Visual criminology is also in ascendance. One of the world's most powerful companies in effect implemented PHDCN SSO procedures for observing public spaces. Google's "Street View" advertises itself by showing a car with a video camera sticking out the top (ours was hidden, and we did not advertise). Their vehicles have roamed many of the world's cities with impressive results. Although lacking investigator control and SSO precision, Google Street View can be and is being used to systematically code a variety of urban street scenes, right down to the level of specific places. As shown in the work of scholars like Candice Odgers, rapid progress is being made in the visual measurement of neighborhood contexts, again at multiple scales (e.g., Odgers et al. 2012). I believe that ecometrics is a unifying idea that has the potential to leverage the GIS, visual, and technology revolutions and help transform how we conduct contextual research in the challenge of a data-rich environment— "big data meets ecometrics" as it were.

10. See http://www.bostonarearesearchinitiative.net/.

11. The geostatistical method of "kriging" is especially relevant to the neighborhood boundary issue. Smooth surfaces can be created that are not limited to pre-defined definitions like census tracts. Blocklevel estimates can be reassembled into any configuration desired by the researcher (Bader and Alshire In press). 
Measurement will only take us so far, of course — one can have big data and small ideas. How we integrate our methods with pressing questions is the real challenge. For the remainder of this address I address what I consider five substantive problems facing criminology: (1) legacies of inequality and developmental neighborhood effects; (2) race, crime, and the new diversity; (3) cognition and context, including the role of social meaning; (4) the measurement and sources of collective efficacy; and (5) extra-local neighborhood effects ("higher-order structures") that arise in complex urban systems. While conceptually distinct, these problems are interdependent and ultimately linked to the idea of contextual causality.

\section{LEGACIES: CONNECTING PAST TO PRESENT}

Pierre Bourdieu began his seminal essay on social capital with a broad observation: "The social world is accumulated history" (1986: 241). A key theme of Great American City is the historical persistence of key forms of social inequality despite massive social change. Consider the profound changes that have occurred over the last 50 years, from riots, population hemorrhaging of central cities, deindustrialization, economic expansion and crime increases in the 1960s to 1970s, to the large increases in immigration, mass incarceration, gentrification, housing boom and crime drop near century's end, to the intensifying globalization and economic collapse of the Great Recession. Through all this neighborhoods remained surprisingly "sticky" in character and largely maintained their place in the pecking order of the city. For example, the poorest neighborhood in Chicago in 1960 was still the poorest neighborhood 40 years later, and during the great crime decline of the late 1990s and into the 2000s, communities with the highest violence rates remained so (Sampson 2012: Chapter 5). At the other end of the spectrum, the 
Gold Coast of the 1920s (Zorbaugh 1929) is still the Gold Coast. It is not that neighborhoods never change, but that they change and reproduce themselves in highly structured ways.

Hard problem \# 1, then, is this: how does the past affect the present? I submit that we do not understand this process well when it comes to context. Criminology is not alone. Orlando Patterson (2004) has argued that one of the great unsolved puzzles in the social sciences is what accounts for strong continuities in social environments. He argues that the dominant focus on change, while central, has obscured the systematic theoretical probing of large-scale historical and cultural continuities. Although he focuses primarily on societies, Patterson's thesis strikes a chord with the literature in community and neighborhood crime studies. Analogous to the persistence of individual differences, we need to ask, why do "criminogenic" contexts reappear time and time again? Legacies of neighborhood inequality and the explanation of persistently high crime areas, in particular, demand our renewed attention.

There is no simple answer or strategy but I posit a number of mechanisms to explain legacies of inequality. Based on principles 1 and 3-5, these include perceived disorder as a mechanism that socially reproduces neighborhood inequality (to which I return later), hierarchy maintenance and negative neighborhood reputation (stigma), and legal cynicism. I also analyze contextual sources of residential mobility and how neighborhood selection reinforces inequality, such that what we typically view as selection bias is in fact a kind of neighborhood effect.

Overall, I take a life-course perspective at the macro-level, focusing simultaneously on processes of stability and change. The key to this move is not just to model change, for which we have excellent methods, but to get at the mechanisms that link the past to the present. ${ }^{12}$

12. The crime rate of a neighborhood 20 years ago does not directly explain its current rate, for example, just as an individual's criminality in the past does not directly cause the present. Some readers will recall an earlier literature at the individual level on population heterogeneity versus state dependence. Although 


\section{DEVELOPMENTAL AND INTERGENERATIONAL EFFECTS}

A major dimension of the legacy issue concerns neighborhood effects on individuals that develop over time. In research from the PHDCN we found that childhood exposure to severely disadvantaged communities was linked to diminished verbal ability later in childhood, a lasting negative effect that continues even after moving out of the neighborhood. Specifically, living in concentrated disadvantage depresses the rate of verbal learning by about four "IQ" points, which is roughly equivalent to missing a year of school. This is a lagged effect of context, one that has implications for how we understand the legacy of neighborhood effects.

Recent work by scholars such as Patrick Sharkey has also uncovered important timevarying and intergenerational effects: The key finding is that neighborhood effects depend not only on where individuals live today, but on where they lived in the past and where their parents lived (Sampson et al. 2008; Sharkey 2008; Wodtke et al. 2011). Sharkey (2013), in particular, finds that since the 1970s, a majority of black families have resided in the poorest quarter of neighborhoods in consecutive generations, compared to only 7 percent of white families. This body of research renders invalid the usual strategy in criminology to study current neighborhood conditions while controlling for characteristics such as family supervision, achievement, and employment that instead may be outcomes of past neighborhood deprivation. In a very real sense we can say that neighborhood inequality is socially "inherited."

In short, while intergenerational family research is well established in criminology, we need research on inter and multi-generational neighborhood effects along with study of the cumulative effects of the past in explaining current inequality (see also Mare 2011). Such a move would help get to the bottom of what in the book I call "developmental neighborhood

similar issues arise, I consider the concept of neighborhood propensity as a black box that begs the central question of what explanatory mechanisms link past and present. 
effects." We have methods for the analysis of crime trajectories, to be sure, but what I am after is their explanation at the individual and neighborhoods levels. What we need then is a life course of place and a more rigorous assessment of history in the form of prior neighborhood contexts and how they are revealed in the current lives of both individuals and neighborhoods.

\section{THE DILEMMA OF RACE AND THE NEW DIVERSITY}

The facts about legacies of inequality bring into sharp relief the next big problem: Criminology has not developed a clear understanding or policy solution to profound disparities in criminal violence by race. Racial disparities in crime and criminal justice processing may even be growing. In the first six months of 2012, for example, 201 of the 259 homicide victims in Chicago were African-American, nearly 78 percent even though blacks make up only a third of the city's population (Heinzmann 2012). Perhaps more stark, almost $70 \%$ of black males with less than a high school education will spend time in prison, making incarceration an expected part of the life course (Pettit and Western 2004).

One stab at an explanation was offered fifteen years ago, when William Julius Wilson and I proposed a theory of race and urban inequality to explain the disproportionate representation of African Americans as victims and offenders in violent crime (Sampson and Wilson 1995). Our thesis was that community-level patterns of racial inequality give rise to the concentration of the truly disadvantaged, which in turn leads to structural barriers and cultural adaptations that undermine social organization and ultimately the control of crime. We pursued this logic to argue that the community-level causes of violence are the same for both whites and blacks - known in the literature as the "racial invariance" thesis — but that racial segregation by community differentially exposes members of minority groups to violence-inducing and 
violence-protecting social mechanisms, explaining black-white disparities in violence. I will not attempt a detailed review here, but I think it is fair to say that the evidence is supportive - there is wide variability in crime rates among white and black communities with robust similarity in key predictors (Krivo and Peterson 2000). Neighborhood factors correlated with race also explain a significant proportion of the black-white racial gap in violence among individuals (Sampson, 2012: 249).

The problem, however, is that spatial inequality by race and place makes fair comparisons between whites and blacks almost impossible. Almost a third of black children in Chicago live in the upper quartile of concentrated disadvantage - for whites the percentage is zero. ${ }^{13}$ At the upper end, white working-class areas do better than the highest-income black neighborhoods when it comes to the economic status of near neighbors, and spatial advantage extends to social interactional and criminal justice processes. For example, among neighborhoods with high collective efficacy, almost $100 \%$ of predominantly white neighborhoods were situated near other high-efficacy neighborhoods compared to less than half of black or Latino neighborhoods. Spatial incarceration differentials are even more disparate (Sampson, 2012: 114). Because of larger processes of segregation and migration, then, even when African American neighborhoods (and, to a lesser extent, Latino neighborhoods) generate collective efficacy, or when they achieve middle-class status, their residents still face the added challenge of being situated in a wider environment characterized by social and criminal justice disadvantage. The situation of white neighborhoods is nearly the opposite — even when they are at high risk because of internal characteristics, their residents benefit from nearby areas. Although I hypothesize that spatial inequality in both disadvantage and social processes are 13. Sampson et al. (2008). Comparing black with white neighborhoods in segregated American cities is thus to compare apples and oranges on key predictors of violence (see also Peterson and Krivo 2010). Poor black neighborhoods for the most part have no white counterparts (Sampson, 2012: 249). 
central to explaining racial disparities, "counterfactual" tests of this thesis are hard to achieve because of the very inequalities at issue.

\section{IMMIGRATION AND THE CHANGING CITY}

Not only do racial disparities and inequalities remain, black-white distinctions are not sufficient for $21^{\text {st }}$ century America. A new reality of ethnic diversity has emerged, bringing with it further questions and puzzles. Latino Americans are now the largest minority group at almost 15 percent of the population, and immigration has neared peak levels historically. Reaching a demographic "tipping point," minority babies also now outnumber white infants according to projections from the U.S. Census (Frey 2011)—whites are thus in line to become the nation's minority in the not too distant future. Perhaps unexpectedly, the United States is not only increasingly diverse in our nation's cities, but in suburbs and rural towns as well.

As the historian Michael Katz (2012: 100) has recently argued, the explosion of immigration has "irrevocably smashed the black/white frame." Indeed, immigration has reshaped America and is now reshaping the world in ways that demand criminological attention. Once again the puzzles are big: why are first-generation immigrants, who are disproportionately poor, less likely to be involved in crime and violence than the better-off native born? What is the macro-level effect of immigration on U.S .crime rates? Although the Sampson-Wilson thesis has focused mainly on blacks and whites, can the "racial invariance" thesis be applied to ethnicity and crime? What role does spatial context play in the new immigration and patterns of diversity?

For the May issue of the Annals of the American Academy of Political and Social Science, John MacDonald and I commissioned some of the most meticulous research to date about the effects of immigration on a cross section of American communities — urban, suburban and rural (MacDonald and Sampson 2012). The scholars who participated were in agreement: 
while new immigrants are poorer than the general population and face considerable hardship, there is no evidence that they have reshaped the social fabric in harmful ways. Combined with findings in Great American City, I would further hypothesize that the large influx of firstgeneration immigrants may reflect a diffusion process with spillover effects or externalities, such as economic renewal in formerly poor areas and the diffusion of nonviolent social mores. Consider, for example, the finding that first-generation immigrants in Chicago commit almost 50 percent less violence than the third generation, after accounting for their greater poverty and differences along a long list of relevant social characteristics (e.g., income, marital status, and even individual IQ). Not only are recent immigrants (whether white, black, or Latino) less violent, there appears to be a protective contextual effect of concentrated immigration. Moreover, increases in immigration at the neighborhood level are linked to decreases in violence, especially in poorer areas and those with histories of racial segregation and exclusion (Sampson, 2012: 251-259).

Integrating the ANNALS volume and independent recent papers, I would thus argue that immigration is either benign with respect to the social fabric or directly linked to crime declines in neighborhoods, cities and perhaps at the national level. This hypothesis remains to be fully assessed, however, and the racial invariance thesis is less clear when it comes to Latinos. My reading of the data is that while homicide among Latino Americans follows the same general pattern as among blacks and whites in terms of the predictive power of concentrated disadvantage, other predictors of Latino violence may well be unique. ${ }^{14}$ Thus it appears that while the racial invariance thesis can be extended to ethnic variations in community-level

14. The fine-grained distinctions often made in tests of racial invariance may be unduly optimistic. The ratio of signal to noise in crime data is typically too low to focus on much more than qualitative inference (e.g., are relationships in the same direction and significant?). Many tests of invariance also fail to account for the fact that when many factors are analyzed, by chance alone we should expect differences. 
disadvantage and violence, there are differences by other characteristics and the number of studies is small (Steffensmeier et al. 2010). The problem of immigrant exposure to the U.S. over time is also a big question: Will lower crime rates in the first and second generation endure?

Increases in diversity and immigration remain a criminological challenge for another reason. Residents perceive more disorder when there are more immigrants (Sampson 2012, chapter 6), and Robert Putnam has provided sobering evidence that neighbors are less trusting the more diverse their neighborhoods (Putnam 2007). At the international level, changes in welfare provisions tend to decline as societies become more diverse, and we have seen an increase in social division in the Netherlands, France, and other European countries as a result of immigration and diversity. Substantial social and population change is also turning cities inside out and calling into question traditional urban and criminological models. For example, poverty is increasingly concentrated in the suburbs, wealth is concentrating in the center cities, and gentrification is reshaping many formerly working class and poor areas. U.S. cities are in essence becoming more like many European cities such as Paris. Ehrenhalt (2012) has called this process "The Great Inversion." Although I argue the evidence suggests demographic "revision" is more apt than inversion, we do need to revise (or discard) the notion of "inner city" and consider the many implications of changing diversity for crime and justice (Kirk and Laub 2010).

In sum, cities and neighborhoods are rapidly changing with respect to diversity and immigration. The increasing presence of "global neighborhoods" (Logan and Zhang 2010) opens up a new set of challenges along with the unsolved problems of race and inequality that have long plagued American cities and criminal justice in America. I submit that a focus on neighborhood context, social mechanisms, and spatial inequality is part of the solution. 


\section{COGNITION AND CONTEXT}

Historically, neighborhood research has been driven by structural theories and "objective" indicators such as concentrated poverty and inequality. While this work remains central, many researchers have become increasingly convinced that cultural and cognitive factors play a key role. In recent years the sociology of culture has argued for the role of concepts such as framing, meaning, collective narratives, stigma, and cultural capital in studying low-income urban populations (Kirk and Papachristos 2011; Small et al. 2010). This intellectual move is notable given the famous critique of cultural explanation in criminology by Kornhauser (1978).

Drawing on principles 3-5, I advocate in Great American City for a revised conception of the role of cultural meaning in our understanding of neighborhood context. In one application I focus on symbolic processes and collective perceptions in our conception of neighborhood disorder. My argument leads me to revisit a core assumption of the "broken windows" thesis: I claim that one broken window (appearance) does not necessarily lead to another broken window and in turn future crime (reality). Rather, it depends on where the broken window exists and the larger social meanings associated with that context. Physical cues in themselves are ambiguous.

Several facts support this argument. First, among those living in the same neighborhood, people differed significantly in how much they viewed disorder as a problem. Second, perceptions were systematically shaped by social position, such as education, race, class, and age. Race is particularly salient — whites see disorder as more of a problem than blacks, Latinos, and Asians, even when living in the same environment (see also Hipp 2010). Third, I showed that immigrant concentration and the presence of a large population of African Americans lead all racial/ethnic groups to view disorder as problematic - regardless of how much observed or measured disorder there is in the neighborhood (which we meticulously 
assessed by videotaped observations and based on inter-rater agreement). This finding undermines the common view that seeing is simply a function of what is there, optically speaking, within error and barring perceptual deficit. Just as memory is dependent on context, so is what we "see."

The more general takeaway is that it is not only "disorder" itself that matters but how it is perceived as a problem. This proposition can be integrated with the broken windows thesis - in fact norms of disorder and order are part of the original theory and subsequent major statements (Skogan 1990). But the context and production of shared meanings have been taken as largely unproblematic, which is ironic given the history of the broken windows thesis. In the field experiment conducted by Philip Zimbardo (2007) in the 1960s that Wilson and Kelling (1982) cite in their original article, a purposely abandoned car in a Bronx neighborhood was ravaged within minutes by vandals. Zimbardo's team recorded more than 20 destructive incidents on the car overall. By contrast, in a Palo Alto neighborhood nothing happened for five days until the researchers themselves started smashing the car's windows. Zimbardo also reports that one day when it began to rain in Palo Alto a passerby lowered the hood of the abandoned car — "God forbid the engine should get wet!" (Zimbardo 2007: 25)

Thus context was everything even at the dawn of broken windows theory - the same cue of disorder, primed by design to be identical, nonetheless triggered vastly different responses depending on the neighborhood. According to Zimbardo, the Bronx was characterized by distrust, cynicism, and “anonymity of place” (2007:304), what I interpret as a kind of "no man's land" compared to Palo Alto's watchful eyes and norms of ownership of public space. ${ }^{15}$ Norms

15. Wilson and Kelling (1982) also note the anonymity and apparent "no one caring" in the Bronx compared to the "mutual regard" of Palo Alto. 
about order are inherently cognitive and contextual, conditioning responses to what are presumed to be objective markers of disorder.

\section{DISORDER AND LEGACIES OF INEQUALITY}

The cognition-context link bears on the two problems I discussed above-legacies of inequality and race/ethnicity. Neighborhoods with high concentrations of minority, immigrant, and poor residents have historically been hard hit by structural problems of crime and capital disinvestment. These persistent and very public processes are not mirages - they have deep roots in the concrete history of American stratification and segregation, and are not likely to lapse in the face of short-term change or contrary evidence. But perceptions take on a new life and persist when reinforced through social interactions, institutional practices, and collective reputations. In particular, I show that shared perceptions of disorder-independent of observable visible cues (what we think of as "reality") - form a meaningful social property of the environment that influences both individual and neighborhood-level outcomes, including the future poverty level of a neighborhood (controlling for its past poverty and present actual disorder). I also show that an individual's perception of disorder is most influenced not by the present level of observed disorder, his or her own characteristics, poverty, or even the racial composition of the neighborhood. What matters most is the inter-subjective or shared prior beliefs of different residents formed years earlier — in other words, shared priors.

These findings reinforce the symbolic role of neighborhood I discussed earlier. Reputations are sticky and the categorization of neighborhoods as "bad" or "disorderly" (or conversely, "good") carries weight that is transmitted over time through institutionalized practices. Often neglected is that the police are at the forefront of dividing up the city into easily understood categories shaped by race and class, and their own visible presence in the community 
may reinforce the priors of residents and further cement a neighborhood's reputation as disorderly, potentially leading to further decline. The self-fulfilling prophecy of stigmatization reflects what I call the looking-glass neighborhood (Sampson, 2012: 365). The socialpsychological concept of the "looking-glass self" posits that a person's individual self grows out of society's interpersonal interactions and the perceptions of others. Moving up a level, I argue that the looking-glass neighborhood is a mechanism that shapes the "appearance order" of the contemporary city. As I show in the book, physical cues in a neighborhood are weakly related to its crime and future poverty trajectory once shared perceptions of disorder are controlled. I therefore propose that collectively shaped perceptions of disorder, along with persistent legal cynicism, another cultural mechanism that I consider important but set aside, ${ }^{16}$ are underappreciated social mechanisms behind the durable legacies of inequality I highlighted earlier. According to this theoretical framework, cultural and structural mechanisms are part of the same dynamic historical processes rather than as rigidly competing ideas.

In sum, "seeing" or perceiving disorder is a heterogeneous process whereby residents impute meaning depending on the contexts and interactions they are observing, in addition to their own characteristics. Wikström et al. (2012) make a similar point on the importance of the perception process, although in their view individual morality is of greater interest. Regardless of the specific hypothesized mechanism, criminology faces a challenge of integrating cultural mechanisms, cognition, and context that will require a new infusion of research. This challenge bears directly on the next theme I take up, the role of norms and collective efficacy.

16. In communities with high legal cynicism and the perceived irrelevance of moral rules, violence is higher. This association is reinforced by disadvantage, suggesting a feedback loop that feeds further cynicism and behavior outside of the law (for example, using violence to settle disputes). Recent research shows that legal cynicism helps explain the persistence of violence in certain communities and racial disparities in violence (Kirk and Papachristos 2011; Sampson 2012; Sampson and Bartusch 1998). 


\section{COLLECTIVE EFFICACY IN A COSMOPOLITAN WORLD}

Born of classic social disorganization theory (Bursik 1988; Kornhauser 1978) and the Chicago School of urban sociology (Short 1971), collective efficacy refers to processes of informal social control and social cohesion among residents. Our conception of collective efficacy (CE) was accompanied by a theoretically driven measurement strategy that tapped both behavior and norms - the "ecometrics" of CE as it were. Resident-based reports of trust, helping behavior, and the collective willingness to do something about public problems all clustered together at the neighborhood level and were measured reliably by a summary scale. In neighborhoods that were otherwise similar, those with higher levels of collective efficacy had lower rates of crime. This general finding was replicated in Stockholm, Sweden and it arises in a number of other international contexts, suggesting that Chicago is not unique. Collective efficacy is also quite stable over time and predicts future variations and changes in crime, adjusting for neighborhood compositional differences. Highly efficacious communities do better on other things as well, including birth weight, rates of teen pregnancy, and infant mortality, suggesting a general link to health. Whether rich or poor, white or black, I have therefore argued that collective efficacy signals a community on a trajectory of wellbeing.

Many questions nonetheless remain. One is measurement related: How is collective efficacy best measured? My answer is that collective efficacy is a theory of process and not simply a measure. For example, different measures of cohesion are possible and I certainly think future research should not be strictly bound by our original operationalization. ${ }^{17}$ I would

17. For example, there is some dispute whether control and cohesion yield a single construct or can be separated. The evidence seems to range from moderately strong correlations (e.g., in range of .6) to strong correlations (over .8). Although I would not expect cohesion and control to be tightly coupled in all contexts, estimating independent effects of theoretically similar indicators that are correlated highly and 
emphasize, however, that one of the distinguishing features of collective efficacy theory is a focus on the activation and content of social ties, not just network density. Influenced by Bandura's (1997) emphasis on human agency in self-efficacy, dense personal or even acquaintanceship ties may facilitate collective efficacy, but they are not posited as sufficient and therefore do not form the definitional core of the concept. Acts such as helping neighbors and exchanging advice are examples of activated ties and thus more akin to social cohesion. ${ }^{18}$

I would further emphasize that collective efficacy theory is distinguished by its focus on informal norms of control in public spaces. Extending the concept of efficacy articulated by Bandura (1997), I view shared expectations of conduct in a social setting as tapping the latent capacity for action. Measuring only behavioral acts of control (or order) confounds norms with inducements and opportunities for their execution. As Erving Goffman (1971: 97) argues, social norms are rooted in shared expectations and perceived codes of conduct that arise in the context of everyday interactions (see also Horne 2001: 4). A key argument of collective efficacy theory is that it matters what I think others think, making collective efficacy a kind of deterrence or moral rule — a generalized mechanism of "common knowledge" that goes beyond any single act

measured with error is uncertain in meaning. There is the additional question of the link between the willingness or intent to intervene and actual control. Wickes et al. (2012) find that norms of collective efficacy in Brisbane, Australia do not predict acts of informal control. Their analysis is conducted only among those respondents who define disorder as a "big" problem, however, and they control for reciprocated exchange (or, arguably, "cohesion"). For these reasons the result is perhaps not surprising - expectations of control are likely to predict lower perceptions of disorder in Brisbane as in Chicago (compare footnote 20), and if so, an analysis only in "big problem" areas and that controls for dimensions of cohesion is by design removing significant variation in collective efficacy.

18. In the PHDCN data, the cohesion scale includes reports of whether residents are "willing to help neighbors" or "get along with each other" and is correlated .7 with the scale of reciprocated exchange at the neighborhood level but less than .3 with the density of friend/kinship ties, again substantiating the distinction between systemic ties and their activation. In past work I have thus considered reciprocated exchange (and intergenerational closure) to be interrelated dimensions of a community's collective efficacy for children (Sampson et al. 1999). Alternatively, one could view the sequence of exchange or cohesion leading to social control as describing the overall causal process of collective efficacy. 
of control. ${ }^{19}$ "Don't Snitch," for example, is a social norm about not intervening or contacting the authorities, a form of anti-collective efficacy that can co-exist with strong personal ties and is likely reinforced by neighborhood social interactions.

In sum, collective efficacy is an overarching construct and causal process involving shared expectations about order and control, activated ties, and acts of informal control. How these concepts are measured and inter-relate will vary depending on the research context. ${ }^{20}$

\section{THE ROLE OF ORGANIZATIONS AND TECHNOLOGY}

Another question I am often asked is: how is collective efficacy produced or induced? Although there is no easy answer, one solution is organizations. The evidence in Chicago reveals that the density of nonprofit organizations in a community is directly related to higher collective efficacy, controlling for economic status and friendship ties. One reason is that shared expectations and trust appear to be enhanced by the collective activities of organizations such as neighborhood block groups, tenant associations, and after-school centers. As Mario Small (2009) has argued, simple activities like childcare are often undertaken in organizational settings that create unanticipated opportunities that expose parents to collective goals like fundraising or helping to plan group activities. Consistent with Small, I hypothesize that nonprofit organizations

19. This analytic distinction and the idea of collective efficacy as a moral context has been taken up in the recent work of Wikström and colleagues in testing situational action theory (Wikström et al. 2012: 143).

20. In the PHDCN data, high collective efficacy predicts future perceptions of low disorder controlling for structural characteristics, concurrently observed disorder, and prior perceptions of disorder. The reverse does not hold. Based on this pattern and the present theoretical framework, one might view perceived disorder as either a) an indicator of shared norms of order (e.g., Ross and Mirowsky 1999: 413) and hence a kind of negative collective efficacy or moral reliability (Skogan, 1990: 48), or b) as a mediator of collective efficacy in a developmental process. Logically, if disorder indicates loss of control, then the loss of control comes first, making option $b$ a reasonable integration of collective efficacy and broken windows theory. My concern with prior research is equating cues that we can systematically measure with norms or subjective beliefs about order (Raudenbush and Sampson, 1999). If norms of (dis)order explain crime more than or as much as observed incidents of disorder, which appears to be the case (Sampson 2012: 147), a revised broken windows thesis is necessary. The devil, as always, is in the details. 
and the maintenance of organizational resources generate a web of routine activities that lubricate collective life, although seldom planned as such. This externality is important in large cities where we can only know or socialize with a tiny proportion of our neighbors based on personal effort alone. The organizational effect on collective efficacy and its distinction from dense personal ties leads me to suggest that perhaps the more accurate conceptualization in the contemporary city is "cosmopolitan efficacy" (Sampson, 2012: 367-370).

Nonprofit organizations and their unintended consequences provide a promising way to think about intervention and the response to collective challenges. There is evidence outside of criminology, for example, that a variety of neighborhood organizations have emerged to help rebuild New Orleans after the devastation of Hurricane Katrina, triggering collective efficacy and city renewal at the ground level. Revising somewhat my earlier emphasis on the task specific versus general nature of collective efficacy, I think there is evidence that organizationally induced social capital and collective efficacy are surprisingly general in orientation, especially in responses to natural disasters (Aldrich 2012). I thus hypothesize that helping responses to exogenously induced threats (such as a hurricane, heat wave, or unexpected crime surge) will be greater in neighborhoods with high collective efficacy than in low collective efficacy areas.

One implication is that it is not just about any one type of organization but more the diversity of organizations and their interconnections. Consistent with this prediction, I show that communities with a high density of churches but with a low presence of other organizations or interlocking connections were lower in trust than the more "secular" communities. I also showed that the cohesion among the network of organizational leaders was positively related to collective efficacy, net of economic and racial composition. These findings are another reason to argue that personal ties among residents are not the only pathway to collective efficacy. Drawing 
on principles 3,7 and 8, I thus hypothesize that a diverse breadth of organizations and crosscutting networks that tie them together lead to a more collectively efficacious neighborhood.

Technology and the sorts of "big data" I discussed earlier can also play a role. There is growing evidence that the boom in social media and networks that connect users globally does not undermine local connections. "Wired" residents are physically concentrated by neighborhood (Sampson 2012: 18) and they are disproportionately connecting about local community (Hampton and Wellman 2003). This ironic fact has broad import: citizens can now report on their smart phones not just crime but the elements of "broken windows" and a broad array of urban conditions. As noted earlier, we can use such data to tap citizen engagement and custodianship over public spaces. Moreover, many nonprofit organizations and city governments now use web-based tools to enhance neighborhood connections, and some high-tech companies are building social network platforms to enhance opportunities for neighboring and the capacity to collectively solve local problems — again leading to a form of cosmopolitan efficacy.

\section{CRIMINAL JUSTICE}

A final and perhaps unconventional question is what role can the police play in building collective efficacy? There has been considerable speculation about community policing and how the police should better work with the community. But which "community" and what organizations should they partner with and how? What about power differentials and the strong distrust of police and overall legal cynicism among residents of persistently disadvantaged neighborhoods (Kirk and Matsuda 2011; Kirk and Papachristos 2011)? Can legitimate policing build trust? Although fraught with tension, a major problem to solve going forward is to figure out how criminal justice organizations can increase efficacy and reduce cynicism among residents, especially among those with the most contact with the law and distrust of authorities. 
Bringing ex-offenders into the process of building collective efficacy is an especially hard but essential challenge.

\section{HIGHER-ORDER STRUCTURES}

One of the main criticisms of the original Chicago School of urban sociology is that it treated the neighborhood as an isolated entity (or "natural area") and ignored politics (Logan and Molotch 1987) and the State (Wacquant 2008). Although not entirely accurate, this critique is legitimate and given added merit in contemporary cities with highly bureaucratic entities, where organizations and their interests fundamentally shape the distribution of resources and evolution of neighborhoods. It follows that political forces and cross-cutting neighborhood networks and organizational ties are potentially just as important as internal neighborhood characteristics. Spatial models are one solution to get us outside the neighborhood proper, but they remain within the framework of between-community analysis. Hence my last hard problem: neighborhoods are part of a complex, higher-order social and political system.

The problem is at once theoretical and methodological. A vision of higher-order structures and processes does not conform to influential accounts in the social sciences of "methodological individualism" that posit individual choice as the foundation of explanation. I accept the causality of individual action, to be sure, but I argue that neighborhood processes and higher-order structures have their own logic and causality. And while I make no claim that neighborhood-level processes are necessarily the most important, like a cog, they mediate bottom-up and top-down mechanisms for many social phenomena. Unlike a hierarchical model, this conceptualization suggests an underlying process that produces chains of effects at all 
levels - causal processes do not inherently begin at the top or bottom. I thus argue that neighborhoods have downward and upward reaching influences, not just "side to side."

Although hard to study and no one can simultaneously unpack all the moving parts, I believe the evidence supports the conclusion that individual selection is both a neighborhood effect and embedded in a process of higher-order "structural sorting," bringing full circle the integration of individual choice, neighborhood processes, and citywide structure. In particular, I found that neighborhood selection is directly linked to past and present neighborhood characteristics, controlling for individual confounders. I also showed that residential mobility ties across neighborhoods and network ties among elites — community leaders in law, business, politics, law enforcement, religion and education — are not only a function of internal neighborhood-level processes and spatial proximity but instead link multiple neighborhoods across often far-flung sections of the city. Consistent with my initial definition, neighborhoods are thus simultaneously embedded in larger communities and a metropolitan social structure.

\section{CONTEXTUAL CAUSALITY}

The catch is that neither experiments nor advanced statistics are a simple solution to this kind of causation, nor, I argue, to social life in general. Consider, for example, the influential idea of an unbiased estimate of a single causal parameter, usually at the individual level and often with individuals "nested" within neighborhoods, with the added assumption of independence or lack of social connections among neighborhoods. Yet the hierarchy and assumption of independence collapse when causality cuts across units and levels. Unlike medical treatments that approximate a closed system, human behavior in social settings is interdependent —nothing is ever truly "held constant." Although recognition of interdependence and interaction effects is not a new insight, I believe I have offered credible evidence that much 
of social life is interdependent in underappreciated spatial forms, with enduring force, and in cross-cutting ways. Studying this kind of interlocking social world over time demands a theoretical stance and multifaceted analytic approach different than the stylistic version of much contemporary research, in which neighborhood effect is taken to mean the statistical or experimental "downward" effect of a specific neighborhood characteristic on some individual behavior (or even neighborhood unit) usually at one point in time.

Rejecting methodological individualism as the dominant paradigm for criminology, I argue that while individuals are the ultimate actors, causality resides at the social level. Here I side with disciplines such as public health and demography — the real action for the problems I have addressed is at the level of institutions, networks, shared cognition, and populations. The State's political role in amplifying or attenuating neighborhood effects is also important to incorporate (Wacquant, 2008). To confront causality in complex dynamic systems and the higher-order structures within which individuals and neighborhoods are embedded is the hardest problem of all I have tackled in this address, but the idea of contextual causality offers exciting opportunities for the development of new models of explanation and ultimately the design of holistic place-based interventions—-the agenda of neighborhood translational criminology. ${ }^{21}$

\section{CONCLUSION}

In this address I have covered a number of problems and puzzles that I consider important for criminologists to tackle. These have ranged widely and many may seem daunting. Issues such as

21. For an attempt to integrate neighborhood and interlocking or higher-order structures and a discussion of the implications for placed-based interventions, see Sampson (2012: Chapters 13-14 and 17).

Promising analytic approaches include the use of agent-based models of neighborhood change (Bruch and Mare 2006) and comparative methods for "conjunctural causality" (Ragin 1987) that allow for heterogeneity in causal processes over time. I plan in a future paper (Sampson and Winship 2013) to tackle methods of contextual causality in greater depth and explore implications for how to think about the implementation and evaluation of criminal justice policy. 
the reproduction of inequality, how to define and what produces collective efficacy, race and crime, the changing city, immigration and the new diversity, cognition and context, politics, and social causality in complex systems - these are clearly not simple problems and no one study or empirical test is possible. But I hope to have offered a unified framework that by "relentlessly focusing on context" and guided by a set of associated principles, will point to possible solutions.

At the same time, I believe the identification of hard unsolved problems is an equally important part of the scientific process. There is precedent for my optimism. In the summer of 1900, the German mathematician David Hilbert delivered a lecture in Paris that came to motivate the field of mathematics for decades to come. In his simply titled address, "Mathematical Problems," Hilbert presented 23 problems at the leading edge of mathematics that he thought would take a century or more to solve, what later became known as "Hilbert Problems." Some of Hilbert's problems were so hard they are still being worked on, as he predicted. But Hilbert was not a pessimist. He believed that unsolved questions were the hallmark of a discipline with vitality and his vision was almost impossibly optimistic, radical even. Consider his argument: "Is this axiom of the solvability of every problem a peculiarity characteristic of mathematical thought alone, or is it possibly a general law inherent in the nature of the mind, that all questions which it asks must be answerable?...This conviction of the solvability of every mathematical problem is a powerful incentive to the worker. We hear within us the perpetual call: There is the problem. Seek its solution.” (Hilbert 1902: 445). Lo and behold many of Hilbert's hard problems were soon solved. Others took more than a half century but were ultimately solved. While some problems are still unresolved to this day, what is inspiring about Hilbert was the bold claim motivating his challenge. 
Criminology has its own set of hard problems, some that have long stymied us like race and crime, while others are fresh, like the challenges imposed by the new diversity and the diverging fates of American cities. But social problems are not like math—they are much harder! So it is with some trepidation that I end where I began, on an optimistic note. By offering a set of hard problems, I am assuming, like Hilbert, that they are to be embraced and have the capacity to energize us for the future. I confess to worries about the individual-level narrowness of much current scholarship, but I retain a faith in criminology's intellectual vitality and capacity, and I believe a turn to a truly contextual criminology will advance our knowledge. I thus encourage a new generation of scholars to venture forth with a renewed sensitivity to the hard problems of neighborhood inequality and the many puzzles of place. 


\section{REFERENCES}

Aldrich, Daniel P. 2012. Building Resilience: Social Capital in Post-Disaster Recovery. Chicago: University of Chicago Press.

Bader, Michael D. M. and Jennifer Alshire. In press. "Improving Measurements of Neighborhood Attributes at Multiple Spatial Scales Using the Geostatistical Method of Kriging." Sociological Methodology.

Bandura, Albert. 1997. Self Efficacy: The Exercise of Control. New York: W. H. Freeman.

Bourdieu, Pierre. 1986. "The Forms of Capital." Pp. 241-58 in Handbook of Theory and Research for the Sociology of Education, edited by J. Richardson. New York: Greenwood.

Bruch, Elizabeth E. and Robert D. Mare. 2006. "Neighborhood Choice and Neighborhood Change." American Journal of Sociology 112:667-709.

Bursik, Robert J. 1988. "Social Disorganization and Theories of Crime and Delinquency: Problems and Prospects." Criminology 35:677-703.

Castells, Manuel. 2000. "Toward a Sociology of the Network Society." Contemporary Sociology 29:693-699.

Ehrenhalt, Alan. 2012. The Great Inversion and the Future of the American City. New York: Alfred A. Knopf.

Frey, William H. 2011. "America Reaches Its Demographic Tipping Point." Washington, D.C.: Brookings Institution.

Fry, Richard and Paul Taylor. 2012. "The Rise of Residential Segregation by Income." Washington, D.C.: Pew Research Center.

Gieryn, Tom. 2000. "A Space for Place in Sociology." Annual Review of Sociology 26:463-496. Giles, Jim. 2012. "Computational Social Science: Making the Links." Nature 488:448-450. 
Goffman, Erving. 1971. Relations in Public. New York: Basic.

Gouldner, Alvin W. 1970. The Coming Crisis of Western Sociology. New York: Basic Books.

Hampton, Keith and Barry Wellman. 2003. "Neighboring in Netville: How the Internet Supports

Community and Social Capital in a Wired Suburb." City and Community 2:277-311.

Heinzmann, David. 2012. "Homicide Numbers Reveal Stark Contrast: African-Americans

Hardest Hit by Spike in Violence, Deaths in Chicago." Chicago Tribune, July 12.

Hilbert, David 1902. "Mathematical Problems." (Lecture Delivered before the International

Congress of Mathematicians at Paris in 1900, English Translation by Mary W. Newson).

Bulletin of the American Mathematical Society 8:437-479.

Hipp, John R. 2007. "Block, Tract, and Levels of Aggregation: Neighborhood Structure and

Crime and Disorder as a Case in Point." American Sociological Review 72:659-680.

Hipp, John R. 2010. "Resident Perceptions of Crime and Disorder: How Much Is "Bias," and

How Much Is Social Environment Differerences?" Criminology 48:475-508.

Horne, Christine. 2001. "Sociological Perspectives on the Emergence of Norms." Pp. 3-34 in

Social Norms, edited by M. Hechter and K.-D. Opp. New York: Russell Sage Foundation.

Janowitz, Morris. 1967. The Community Press in an Urban Setting: The Social Elements of

Urbanism. Chicago: University of Chicago Press.

Jaye, Michael C. and Ann Chalmers Watts (Eds.). 1981. Literature and the Urban Experience.

New Brunswick, NJ: Rutgers University Press.

Katz, Michael B. 2012. Why Don't American Cities Burn? Philadelphia, PA: University of

Pennsylvania Press. 
Kirk, David S. and John H. Laub. 2010. "Neighborhood Change and Crime in the Modern Metropolis." Pp. 441-502 in Crime and Justice, edited by M. Tonry. Chicago: University of Chicago Press.

Kirk, David S. and Mauri Matsuda. 2011. "Legal Cynicism, Collective Efficacy, and the Ecology of Arrest." Criminology 49:443-472.

Kirk, David S. and Andrew V. Papachristos. 2011. "Cultural Mechanisms and the Persistence of Neighborhood Violence." American Journal of Sociology 116:1190-1233.

Kornhauser, Ruth Rosner. 1978. Social Sources of Delinquency: An Appraisal of Analytic Models. Chicago: University of Chicago Press.

Krivo, Lauren J. and Ruth Peterson. 2000. "The Structural Context of Homicide: Accounting for Racial Differences in Process." American Sociological Review 65:547-559.

Logan, John and Harvey Molotch. 1987. Urban Fortunes: The Political Economy of Place. Berkeley, CA: University of California Press.

Logan, John R. and Charles Zhang. 2010. "Global Neighborhoods: New Pathways to Diversity and Separation." American Journal of Sociology 115:1069-1109.

Looker, Benjamin. 2012. "Visions of Autonomy: The New Left and the Neighborhood Government Movement of the 1970s." Journal of Urban History 38:577-598.

MacDonald, John and Robert J. Sampson. 2012. "The World in a City: Immigration and America's Changing Social Fabric." ANNALS of the American Academy of Political and Social Science 624:6-15.

Mare, Robert D. 2011. "A Multigenerational View of Inequality." Demography 48:1-23. McKenzie, R. D. 1921. "The Neighborhood: A Study of Local Life in the City of Columbus, Ohio." American Journal of Sociology 27:344-363. 
Mumford, Lewis. 1954. "The Neighborhood and the Neighborhood Unit." Town Planning Review 24:256-270.

Odgers, Candice, Avshalom Caspi, Christopher Bates, Robert J. Sampson and Terri E. Moffitt. 2012. "Systematic Social Observation of Children's Neighborhoods Using Google Street View: A Reliable and Cost Effective Method." Journal of Child Psychology and Psychiatry 53:1009-1017.

Patterson, Orlando. 2004. "Culture and Continuity: Causal Structures in Socio-Cultural Persistence." Pp. 71-109 in Matters of Culture: Cultural Sociology in Practice, edited by J. Mohr and R. Friedland. New York: Cambridge University Press.

Peterson, Ruth D. and Lauren J. Krivo. 2010. Divergent Social Worlds: Neighborhood Crime and the Racial-Spatial Divide. New York: Russell Sage Foundation.

Pettit, Becky and Bruce Western. 2004. "Mass Imprisonment and the Life Course: Race and Class Inequality in U.S. Incarceration." American Sociological Review 69:151-69.

Putnam, Robert. 2007. "E Pluribus Unum: Diversity and Community in the 21 st Century: The 2006 Johan Skytte Prize Lecture." Scandinavian Political Studies 30:137-174.

Ragin, Charles C. 1987. The Comparative Method. Berkeley: University of California Press. Raudenbush, Stephen W. and Robert J. Sampson. 1999. "'Ecometrics': Toward a Science of Assessing Ecological Settings, with Application to the Systematic Social Observation of Neighborhoods." Sociological Methodology 29:1-41.

Reardon, Sean F. and K. Bischoff. 2011. "Income Inequality and Income Segregation." American Journal of Sociology 116:1092-1153.

Ross, Catherine E. and John Mirowsky. 1999. "Disorder and Decay: The Concept and Measurement of Perceived Neighborhood Disorder." Urban Affairs Review 34:412-432. 
Sampson, Robert J. 2012. Great American City: Chicago and the Enduring Neighborhood Effect.

Chicago: University of Chicago Press.

Sampson, Robert J. and William Julius Wilson. 1995. "Toward a Theory of Race, Crime, and Urban Inequality." Pp. 37-56 in Crime and Inequality, edited by J. Hagan and R. D.

Peterson. Stanford, CA: Stanford University Press.

Sampson, Robert J. and Dawn Jeglum Bartusch. 1998. "Legal Cynicism and (Subcultural?)

Tolerance of Deviance: The Neighborhood Context of Racial Differences." Law and Society Review 32:777-804.

Sampson, Robert J. and Christopher Winship. 2013. "Making Causal Claims: Principles for a Policy-Relevant Criminology." Paper in progress. Cambridge, MA: Harvard University.

Sampson, Robert J., Jeffrey D. Morenoff and Felton Earls. 1999. "Beyond Social Capital: Spatial Dynamics of Collective Efficacy for Children." American Sociological Review 64:633-660.

Sampson, Robert J., Patrick Sharkey and Stephen W. Raudenbush. 2008. "Durable Effects of Concentrated Disadvantage on Verbal Ability among African-American Children." Proceedings of the National Academy of Sciences 105:845-852.

Sharkey, Patrick. 2013. Stuck in Place: Urban Neighborhoods and the End of Progress toward Racial Equality. Chicago: University of Chicago Press.

Sharkey, Patrick T. 2008. "The Intergenerational Transmission of Context." American Journal of Sociology 113:931-969.

Short, James F., Jr. (Ed.). 1971. The Social Fabric of the Metropolis: Contributions of the Chicago School of Urban Sociology. Chicago: University of Chicago Press.

Skogan, Wesley. 1990. Disorder and Decline: Crime and the Spiral of Decay in American Cities. Berkeley, CA: University of California Press. 
Small, Mario. 2009. Unanticipated Gains: Origins of Network Inequality in Everyday Life. New York: Oxford University Press.

Small, Mario Luis, David J. Harding and Michele Lamont. 2010. "Reconsidering Culture and Poverty." Annals of the American Academy of Political and Social Science 629:6-27.

Smith, Michael E. 2010. "The Archaeological Study of Neighborhoods and Districts in Ancient Cities." Journal of Anthropological Archaeology 29:137-154.

Steffensmeier, Darrell, Jeffrey T. Ulmer, Ben Feldmeyer and Casey Harris. 2010. "Scope and Conceptual Issues in Testing the Race-Crime Invariance Thesis: Black, White, and Hispanic Comparisons " Criminology 48:1133-1170.

Wacquant, Loïc. 2008. Urban Outcasts: A Comparative Sociology of Advanced Marginality. Cambridge, UK: Polity Press.

Weisburd, David, Elizabeth R. Groff and Sue-Ming Yang. 2012. The Criminology of Place: Street Segments and Our Understanding of the Crime Problem. New York: Oxford University Press.

Wickes, Rebecca, John R. Hipp, Elise Sargeant and Lorraine Mazerolle. 2012. "Neighbors, Norms and Actions: What Influences Residents' Informal Social Control Behaviors?" Paper presented at Annual Meeting of the American Society of Criminology. Chicago, IL

Wikström, Per-Olof H., Dietrich Oberwittler, Kyle Treiber and Beth Hardie. 2012. Breaking Rules: The Social and Situational Dynamics of Young People's Urban Crime. Oxford: Oxford University Press.

Wilson, James Q. and George Kelling. 1982. "Broken Windows: The Police and Neighborhood Safety." Atlantic 127:29-38. 
Wodtke, Geoffrey T., David J. Harding and Felix Elwert. 2011. "Neighborhood Effects in Temporal Perspective: The Impact of Long-Term Exposure to Concentrated Disadvantage on High School Graduation." American Sociological Review 76:713 -736.

Zimbardo, Philip. 2007. The Lucifer Effect: Understanding How Good People Turn Evil. New York: Random House.

Zorbaugh, Henry. 1929. The Gold Coast and the Slum: A Sociological Study of Chicago's Near North Side. Chicago: University of Chicago Press.

\footnotetext{
$* * * * * * * * * * * * * * * * * * * * * * * * * * * * * * * * * * * * *$
}

Robert J. Sampson is the Henry Ford II Professor of the Social Sciences at Harvard University and director of the Social Sciences Program at the Radcliffe Institute for Advanced Study. His research has focused primarily on the development and assessment of a life-course theory of crime, race and urban inequality, neighborhood effects, methods for the study of context, and the social structure of the modern city. His most recent book-Great American City: Chicago and the Enduring Neighborhood Effect — was published by the University of Chicago Press in 2012. 